\title{
Analisis Skenario Penambahan Frontal Frame pada Jetty 1 untuk Menurunkan Integrated Port Time (IPT) di Integrated Terminal ABC
}

\author{
*Ibnu Lukman Pratama \\ Politeknik Energi dan Mineral (PEM Akamigas) \\ Dwi Nurma Heitasari \\ Politeknik Energi dan Mineral (PEM Akamigas) \\ Ayu Praditha \\ Politeknik Energi dan Mineral (PEM Akamigas) \\ *Ibnulukman_pratama@esdm.go.id
}

\begin{abstract}
Abstrak
Untuk menjamin kelancaran kegiatan operasional perkapalan di pelabuhan, PT Pertamina (Persero) memberlakukan standarisasi batasan waktu operasi kapal dipelabuhan atau lebih dikenal dengan Integrated Port Time (IPT). Seiring dengan penerapannya, terjadi beberapa kendala salah satunya yaitu waktu tunggu kapal yang lama di pelabuhan, menyebabkan kapal semakin lama berada di pelabuhan sehingga membuat biaya operasional kapal meningkat dan voyage (call) kapal tidak akan mencapai optimal dalam waktu yang telah ditentukan. Sehingga dalam hal ini diusulkan penambahan frontal frame pada jetty 1 agar kapal-kapal yang mengantri untuk sandar ke jetty 2 juga dapat melakukan penyandaran di jetty 1 . Dalam usulan penambahan frontal frame ini, diusulkan 3 skenario pergerakan kapal. Untuk mengetahui skenario mana yang paling efektif dalam mengurangi antrian kapal, menghemat IPT dan biaya sewa kapal, maka perlu diketahui hasil dari masing-masing skenario. Dalam hal ini penulis menggunakan metode simulasi diskrit yang dibantu dengan software Arena 14.0. Hasil dari simulasi menunjukkan bahwa skenario 2 merupakan skenario yang paling efektif dalam memberikan penghematan dibandingkan dengan skenario lainnya. Hasil dari skenario 2 menunjukkan bahwa terjadi penghematan IPT yang semula 52 jam menjadi 40,38 jam, penghematan biaya sewa kapalnya adalah sebesar Rp 13.968.817.396, dan utilitasnya yang semula masing-masing jetty adalah sebesar 0,53 dan 0,81 .
\end{abstract}

Key Word : Kapal, Integrated Port Time (IPT), Jetty, Frontal frame

\section{Pendahuluan}

Seiring dengan berkembangnya zaman, jumlah penduduk dan industri di Indonesia juga berkembang dan melaju dengan pesat sehingga berdampak langsung terhadap meningkatnya kebutuhan energi nasional. Dikutip dari data Dewan Energi Nasional dalam bukunya yang berjudul "Outlook Energi Nasional (OEI) 2019", total konsumsi energi final (tanpa biomasa tradisional) tahun 2018 adalah sekitar 114 MTOE terdiri dari sektor transportasi 40\%, kemudian industri 36\%, rumah tangga 16\%, komersial dan sektor lainnya masing-masing 6\% dan 2\% (DEN, 2019). Dalam hal ini, Pemerintah bertanggung jawab atas pemenuhan kebutuhan energi nasional, sehingga dalam melaksanakan tugas dan tanggung jawabnya, Pemerintah menugaskan salah satu perusahaan energi yang menyelenggarakan usahanya di sektor minyak dan gas bumi di Indonesia untuk mendukung ketahanan energi nasional yaitu PT Pertamina (persero). Salah satu fungsi utama PT Pertamina (Persero) adalah melakukan pendistribusian Bahan Bakar Minyak (BBM), gas bumi, energi baru dan terbarukan ke seluruh penjuru Indonesia dan fungsi tersebut dilakukan oleh Direktorat Pemasaran dan Niaga. 
Salah satu sarana angkut yang digunakan oleh PT Pertamina (Persero) adalah menggunakan kapal, baik itu kapal milik ataupun kapal sewa (charter). Untuk menjamin kelancaran kegiatan operasional perkapalan di pelabuhan, PT Pertamina (Persero) memberlakukan standarisasi batasan waktu operasi kapal dipelabuhan atau lebih dikenal dengan Integrated Port Time (IPT). Salah satu tujuan diberlakukannya Integrated Port Time (IPT) ini adalah untuk menjamin kelancaran operasi, mengurangi waktu tunggu (waiting time) dan melakukan kegiatan bongkar muat secara simultan di seluruh pelabuhan (PT Pertamina Shipping, 2010). Seiring dengan penerapannya, terjadi beberapa kendala salah satunya yaitu waktu tunggu kapal yang lama di pelabuhan, menyebabkan kapal semakin lama berada di pelabuhan sehingga membuat biaya operasional kapal meningkat dan voyage (call) kapal tidak akan mencapai optimal dalam waktu yang telah ditentukan.

Menurut data IPT 2019, diketahui bahwa jumlah IPT nya mencapai 52 jam, dalam waktu 52 jam tersebut terdapat waktu tunggu kapal yang lama, dimana 50\% lamanya waktu tunggu tersebut disebabkan oleh waiting jetty, karena jumlah kedatangan kapal dengan jenis Small 1 dan Small 2 yang akan bersandar ke jetty 2 lebih banyak dibandingkan kapal yang akan bersandar ke jetty 1 dan kondisi jetty 1 yang hanya bisa menerima kapal jenis GP dan MR sehingga menyebabkan adanya antrian kapal. Terdapat banyak kapal ukuran kecil yang memiliki proyeksi seperti sabuk pelindung pada lambungnya. Bila terjadi kontak langsung terhadap fender, maka fender akan mengalami tekanan sebagian sehingga akan menimbulkan kerusakan serius seperti retak atau patah. Untuk mencegah hal tersebut, Bridgestone (2011) menyarankan untuk melindungi fender dengan frontal frame dan frontal pad. Sehingga dalam hal ini diusulkan penambahan frontal frame, yakni kerangka baja yang berfungsi untuk melindungi fender dari kerusakan yang serius seperti retak atau patah akibat mengalami tekanan sebagian apabila terjadi kontak secara langsung dengan lambung kapal dan berfungsi pula untuk memperluas bidang kontak antara fender dengan lambung kapal (Wahid, 2011). Penambahan frontal frame pada jetty 1 agar kapal-kapal yang mengantri untuk sandar ke jetty 2 juga dapat melakukan penyandaran di jetty 1. Dalam usulan penambahan frontal frame ini, diusulkan 3 skenario pergerakan kapal. Untuk mengetahui skenario mana yang paling efektif dalam mengurangi antrian kapal, menghemat IPT dan biaya sewa kapal, maka perlu diketahui hasil/ output dari masing-masing skenario. Dalam hal ini penulis menggunakan metode simulasi diskrit yang dibantu dengan software Arena 14.0 sebagai tools karena software tersebut memberikan kemudahan dalam pembuatan model yang tidak harus lagi membuat perangkat lunak berupa perintah, melainkan cukup menggambarkan dan memasukkan variabel data parameternya (Bobby, 2015)

Berdasarkan permasalahan tersebut, secara garis besar penelitian bertujuan untuk : 1). Mengidentifikasi model simulasi eksisting dari proses aktivitas kapal yang diterapkan di Integrated Terminal ABC, 2). Menentukan skenario penambahan frontal frame pada jetty 1 untuk mengurangi Integrated Port Time (IPT) di Integrated Terminal ABC, 3). Menganalisis hasil simulasi dari proses aktivitas kapal setelah penambahan frontal frame pada jetty 1 di Integrated Terminal $\mathrm{ABC}$.

\section{Metode Penelitian Jenis Penelitian}

Penelitian ini merupakan penelitian deskriptif kuantitatif, dimana penelitian ini dilakukan untuk menangkap permasalahan yang terjadi di Integrated Terminal ABC kemudian hasilnya dideskripsikan dalam bentuk angka serta untuk menganalisis skenario penambahan frontal frame pada jetty 1, yaitu menganalisis waktu sistem kapal (IPT), biaya sewa kapal dan utilitas jetty setelah melakukan penambahan frontal frame dengan menggunakan software Arena yang bertujuan mengurangi Integrated Port Time (IPT) di 
Pelabuhan dan untuk memaksimalkan voyage (call) kapal dalam waktu yang telah di tentukan.

\section{Teknik Pengumpulan Data}

Jetty eksisting yang terdapat di Integrated Terminal ABC sebanyak 3 jetty. Jetty 1 untuk discharge BBM dari kapal jenis Medium Range (MR), General Purpose (GP) dan kapal dari jenis tongkang (SPOB) dengan kapasitas maksimal hingga 35000 DWT, jetty 2 untuk loading discharge BBM dari kapal jenis Small 1, Small 2 serta kapal pengangkut LPG dan kapal dari jenis tongkang (SPOB) dan tug boat, sedangkan jetty 3 untuk loading discharge LPG dengan kapasitas maksimal 1500 DWT. Dalam penelitian ini kemudian diusulkan penambahan frontal frame pada jetty 1 agar kapal dengan jenis Small 1 dan Small 2 dapat sandar di jetty 1 untuk melakukan proses aktifitas loading discharge. Penambahan frontal frame ini dilakukan dengan maksud untuk mengurangi antrian kapal untuk masuk ke jetty 2 dan waktu sistem kapal (IPT) di pelabuhan.

Setelah semua data yang dibutuhkan sudah terpenuhi selanjutnya dilakukan pengolahan data. Data IPT yang telah di dapatkan, pertama kali akan dilakukan pengolahan data mentah. Setiap jenis data yang dikumpulkan dalam penelitian ini adalah data sekunder integrated port time yang merupakan total waktu labuh kapal menghabiskan waktu di pelabuhan dihitung sejak kapal menyampaikan ATA (Actual Time Arrival) atau NOR (Notice of Readiness) tender + 6 jam sampai dengan kapal ATD (Actual Time Departure) atau full away. Adapun pengolahan data mentah ini dilakukan dengan cara : 1) Data kapal yang di dapat kemudian dikumpulkan berdasarkan tipe kapal yang masuk ke jetty, dengan demikian data disajikan terpisah berdasarkan sarana tambat yang digunakan oleh kapal. Kemudian mengeliminasi data kapal yang aktivitas operasinya tidak terkait dengan skenario penambahan frontal frame pada jetty 1, yaitu dengan mengeliminasi kapal-kapal yang bersandar di jetty 3 dimana jetty 3 hanya dapat menerima penyandaran kapal untuk proses loading discharge LPG, yang mana hanya kapal pengangkut LPG saja yang dapat sandar pada jetty 3 sedangkan pengangkut BBM tidak, sehingga tidak memiliki keterkaitan dengan skenario penambahan frontal frame pada jetty 1 . Sehingga data yang akan diolah ke tahap selanjutnya adalah data kapal yang hanya bersandar di jetty 1 dan jetty 2 selama 1 tahun, 2) kemudian juga mengeliminasi data yang keterangan waktu proses mulai dari ATA s/d ATD tidak lengkap dalam pencatatannya, 3) Setelah itu dilakukan pengujian keseragaman data dan kecukupan data untuk meningkatkan validitas data tersebut. Uji keseragaman data ini menggunakan Control Chart untuk mengetahui ada tidaknya data yang di luar batas kendali (outlier) sedangkan untuk mengetahui apakah data kapal yang nantinya digunakan sebagai input di Arena sudah cukup atau belum, dapat di ketahui melalui perhitungan. Adapun rumusnya yaitu :

$$
N^{\prime}=\left[\frac{\frac{k}{s} \sqrt{N \cdot \sum X i^{2}-\left(\sum X i\right)^{2}}}{\sum X i}\right]^{2}
$$

\section{Simulasi Kondisi Eksisting}

Setelah data-data waktu setiap aktivitas kapal telah dikumpulkan, maka perlu ditentukan jenis distribusinya. Penentuan tersebut menggunakan input analyzer yang merupakan salah satu fasilitas yang tersedia dalam software Arena 14.0. Data yang telah diolah tersebut kemudian digunakan untuk dimasukkan ke model simulasi, kemudian juga membuat diagram Activity Cycle Diagram (ACD) sistem eksisting yaitu bahasa/ grafik yang memodelkan sistem dengan menunjukkan interaksi antar elemen dengan perubahan secara diskrit terhadap waktu. ACD ini nantinya akan dibandingkan dengan model yang telah 
dibangun di arena untuk menyatakan apakah model telah terverifikasi atau tidak. Setelah itu kemudian memodelkan sistem proses aktivitas kapal di pelabuhan dimulai dari ATA s/d ATD dengan modul-modul yang telah disediakan oleh software Arena 14.0 untuk mendeskripsikan aktifitas-aktifitas yang telah dibuatkan logikanya pada Activity Cycle Diagram (ACD). Model yang telah dibuat di verifikasi dengan cara membandingkan dengan diagram alur $(A C D)$ yang telah dibuat sebelumnya. Verifikasi model simulasi dapat dilakukan dengan memilih menu "check model" pada program Arena 14.0 dari dialog box yang muncul maka bagian dari model yang dijalankan (run) sudah tidak terdapat error dan simulasi dapat dijalankan yang artinya model berjalan sesuai dengan logika diagram ACD. Apabila model dinyatatakan belum terverifikasi maka harus kembali ke langkah analisis dan pengolahan data, tetapi apabila model dinyatakan sudah terverifikasi simulasi boleh di jalankan.

Setelah model simulasi kondisi eksisting telah berhasil dijalankan, maka langkah selanjutnya adalah melakukan uji validasi model. Validasi ini bertujuan untuk mengetahui kesesuaian antara hasil simulasi dengan gejala atau proses yang ditirukan. Suatu model dikatakan valid jika struktur dasar dan polanya dapat menggambarkan perilaku sistem nyata, atau dapat mewakili dengan cukup akurat, data yang dikumpulkan sehubungan dengan sistem nyata atau asumsi yang dibuat berdasarkan referensi sesuai cara sistem nyata bekerja. Model simulasi dijalankan dengan durasi 365 hari dengan 10 replikasi untuk memperoleh variabilitas data dan kemudian kedatangan kapal yang diperoleh dari 10 kali replikasi simulasi dibandingkan dengan data kedatangan kapal kondisi eksisting. Metode yang digunakan untuk pengujian validasi model pada penelitian ini adalah uji-t independent, dimana memiliki hipotesa awal sebagai berikut :

○ $\mathrm{H}_{0}=\mu 1-\mu 2=0$

○ $\mathrm{H} 1=\mu 1-\mu 2 \neq 0$

- Jumlah sampel pada masing-masing populasi (n1) dan (n2) tidak harus sama

○ Variasi antar populasi 1 dengan populasi 2 tidak harus sama $\sigma 1 \neq \sigma 2 \neq \sigma$ Rumus pendekatan validasi :

$$
\mathrm{d} f=\frac{\left(\frac{s 1^{2}}{n 1}+\frac{s 2^{2}}{n 2}\right)}{\frac{\left(\frac{s 1^{2}}{n 1}\right)}{n 1-1}+\frac{\left(\frac{s 2^{2}}{n 2}\right)}{n 2-1}}
$$

Langkah awal penentuan jumlah replikasi dilakukan running sebanyak 10 kali terlebih dahulu untuk mendapatkan error dan standar deviasi, setelah itu berdasarkan perhitungan akan ditentukan kembali jumlah replikasi minimal yang harus dilakukan. Rumus perhitungan jumlah replikasi :

$$
\begin{gathered}
a=1-\text { confidence interval } \\
t_{n-1, \frac{\alpha}{2} \times S} \\
\text { Half width }=\frac{t_{n-1, \frac{\alpha}{2} \times S}}{\sqrt{n}}
\end{gathered}
$$

Error terhadap mean $=$ half width/ mean 
Setelah melakukan validasi kemudian dilakukan analisis terhadap hasil dari simulasi. Setelah program selesai dan dianalisis maka selanjutnya adalah perancangan skenario penambahan frontal frame. Pada tahap ini, dilakukan running simulasi model setelah penambahan frontal frame pada jetty 1 . Selanjutnya akan dilakukan analisa terhadap output yang dihasilkan dari simulasi model sehingga dapat diketahui apakah hasil simulasi tersebut memenuhi kebutuhan yang diinginkan atau tidak. Perhitungan biaya-biaya, dalam hal ini akan dilakukan perhitungan biaya-biaya yaitu biaya sewa kapal kemudian akan dianalisis apakah terjadi penghematan biaya tersebut dengan ditambahkannya frontal frame atau tidak.

\section{Pembahasan}

\section{Frekwensi Kedatangan Kapal di Integrated Terminal ABC}

Menurut data Integrated Port Time (IPT) Pelabuhan, ada 570 kapal yang datang ke Integrated Terminal ABC selama 1 tahun. Pada penelitian ini akan membahas dan menghitung waktu proses aktivitas kapal di pelabuhan yang hanya bersandar di jetty 1 dan jetty 2 dimulai dari ATA sampai dengan ATD, karena jetty 3 tidak dapat digunakan untuk penyandaran kapal-kapal pengangkut BBM namun hanya digunakan khusus untuk melakukan loading discharge LPG sehingga kapal-kapal yang bersandar di jetty 3 tidak memiliki pengaruh terhadap skenario penambahan frontal frame pada jetty 1. Terdapat 5 tipe kapal yang memasuki pelabuhan di Integrated Terminal ABC yaitu Small 1, Small 2, General Purpose, Medium Range dan X. X disini adalah campuran kapal-kapal yang berjenis SelfPropelled Oil Barge (SPOB), Tug Boat dan kapal pengangkut LPG yang biaya operasinya tidak berhubungan dengan rencana penambahan frontal frame pada jetty 1. Data Integrated Port Time disini menunjukkan frekwensi kedatangan kapal yang masuk jetty sampai keluar jetty. Tipe kapal yang masuk ke jetty 1 adalah General Purpose dengan 39 kapal, Medium Range dengan 75 kapal dan X dengan 101 kapal, sedangkan tipe kapal yang masuk ke jetty 2 adalah Small 1 dengan 103 kapal, Small 2 dengan 98 kapal dan X dengan 78 kapal, sehingga total kapal yang bersandar di jetty 1 dan jetty 2 adalah 494 kapal (494 call) dan total IPT yang semula 55 jam menjadi 54 jam. Dari data tersebut dapat diketahui bahwa kapal yang lebih banyak datang ke Integrated Terminal ABC adalah kapal dengan jenis Small 1 dan Small 2 ditambah dengan berbagai kapal lainnya $(\mathrm{X})$ yang membuat adanya antrian kapal menunggu giliran untuk bersandar di jetty 2.

Tabel 1. Data Tonase, Jenis beserta Jumlah Kedatangan Kapal Sewa di Integrated ABC

\begin{tabular}{|c|c|c|}
\hline DWT & Tipe Kapal & $\begin{array}{c}\text { Jumlah Kedatangan } \\
\text { Kapal Sewa }\end{array}$ \\
\hline $1250-3499$ & Small 1 & 96 \\
\hline $3500-6499$ & Small 2 & 99 \\
\hline $6500-24999$ & General Purpose & 35 \\
\hline $25000-45999$ & Medium Range & 69 \\
\hline \multicolumn{2}{|r}{ Sumber : IPT Tahun 2019 (Telah Diolah Kembali) }
\end{tabular}

Data yang dibutuhkan dalam aspek finansial yaitu biaya charter rate sewa kapal. Data rata-rata sewa kapal per harinya dapat dilihat pada tabel di bawah ini. 
INOBIS : Jurnal Inovasi Bisnis dan Manajemen Indonesia

Volume 02, Nomor 04, September 2019

Ibnu Lukman Pratama, Dwi Nurma Heitasari, Ayu Praditha

Tabel 2. Data Charter Rate Sewa Kapal Per Hari

\begin{tabular}{|c|c|}
\hline Tipe & $\begin{array}{c}\text { Charter } \boldsymbol{R} \\
\text { ate/ USD/ Kapal/hari }\end{array}$ \\
\hline Small 1 & 3.125 \\
\hline Small 2 & 5.368 \\
\hline GP & 11.300 \\
\hline MR & 12.140 \\
\hline
\end{tabular}

Sumber : Departemen Suplai dan Distribusi MOR I, 2019 (Telah Diolah Kembali)

\section{Perancangan Skenario Penambahan Frontal Frame Pada Sistem}

\section{Skenario 1}

Pada Skenario 1, ditentukan bahwa kapal Small 1 dan Small 2 yang semula hanya dapat bersandar di jetty 2 juga dapat melakukan penyandaran dan mendapatkan pelayanan di jetty 1. Skenario perbaikan ini dapat dilihat pada gambar di bawah ini, garis berwarna putih menunjukkan kondisi eksisting dan garis berwarna menunjukkan skenario perbaikannya

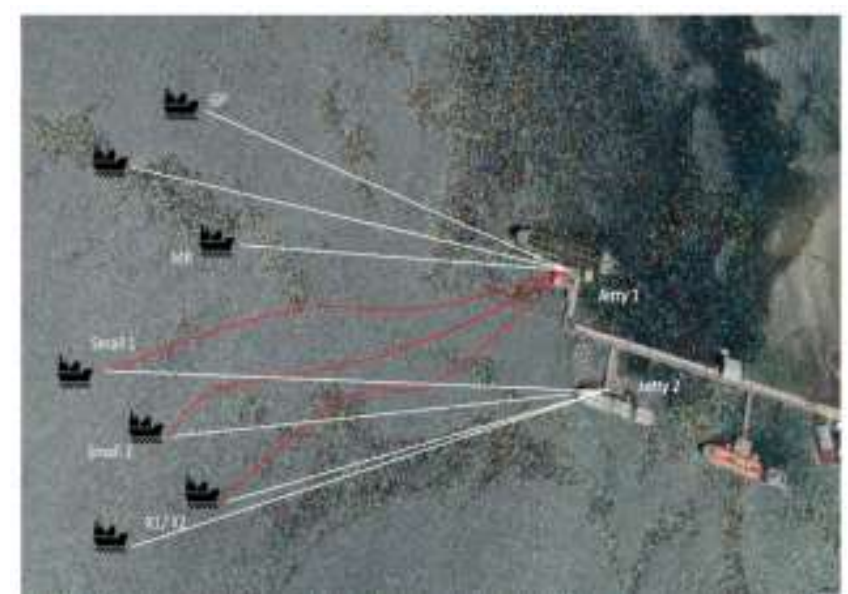

Gambar 1. Skenario 1 Pergerakan Kapal Small 1 dan Small 2 Setelah Penambahan Frontal Frame pada Jetty 1 (Sumber : Hasil Olahan, 2019)

Model Simulasi Skenario 1 dapat dilihat pada gambar di bawah ini

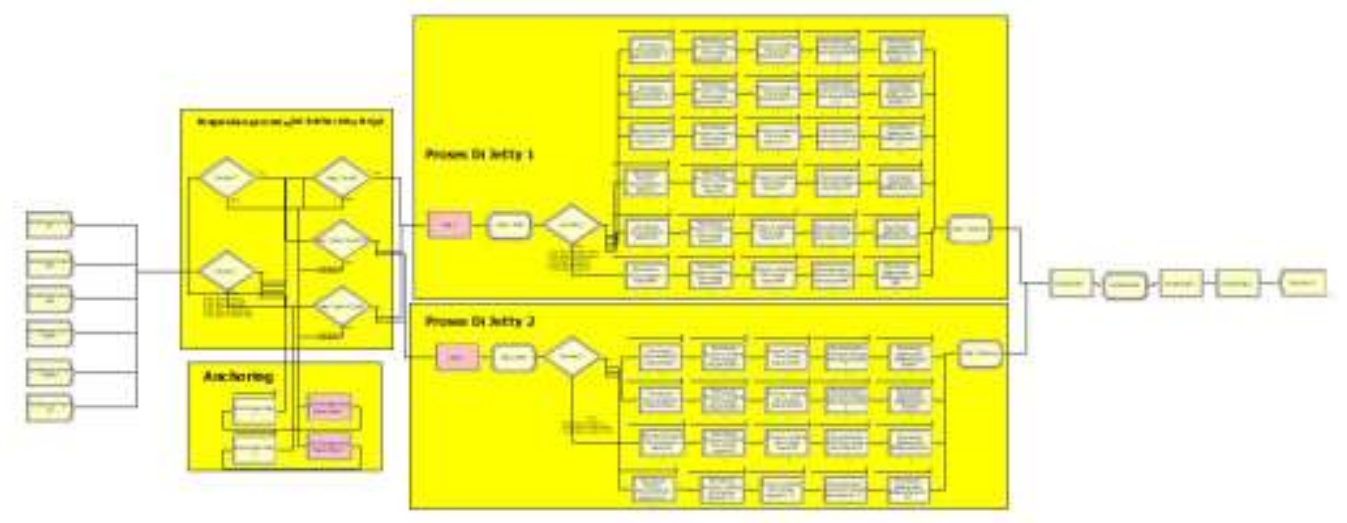

Gambar 2. Model Simulasi Skenario 1 (Sumber : Simulasi Arena Skenario 1, 2019) 
Setelah dilakukan running pada model simulasi skenario 1 didapatkan hasil bahwa waktu rata-rata yang dihabiskan kapal selama berada di pelabuhan mencapai 41,5 jam, waktu tunggu yang dihabiskan kapal untuk masuk ke jetty 1 adalah selama 27,25 jam sedangkan untuk masuk ke jetty 2 adalah selama 31,58 jam dan utilitas jetty 1 adalah sebesar 0,79 sedangkan jetty 2 adalah sebesar 0,55. Adapun kapal yang dilayani adalah sebanyak 493 kapal. Data hasil running pada model simulasi skenario 1 dapat dilihat dibawah ini,

\begin{tabular}{ll|}
\hline & \multicolumn{1}{c}{ Values Across All Replications } \\
\hline Unnamed Project & \\
\hline Replications: $10 \quad$ Time Units: Hours
\end{tabular}

\section{Key Performance Indicators}

$\begin{array}{lc}\text { System } & \text { Average } \\ \text { Number Out } & 493\end{array}$

Gambar 3. Jumlah Kapal yang Dilayani Dari Hasil Simulasi Skenario 1 (Sumber : Hasil Simulasi Data IPT dengan Arena, 2019)

\begin{tabular}{lrrrrrr} 
Total Time & Average & Half Width & $\begin{array}{r}\text { Minimum } \\
\text { Average }\end{array}$ & $\begin{array}{r}\text { Maximum } \\
\text { Average }\end{array}$ & $\begin{array}{r}\text { Minimum } \\
\text { Value }\end{array}$ & $\begin{array}{r}\text { Maximum } \\
\text { Value }\end{array}$ \\
\hline Kapal GP & 50.8969 & 4.43 & 43.5469 & 61.3448 & 15.1121 & 145.88 \\
Kapal MR & 58.8091 & 2.77 & 53.5593 & 65.7504 & 17.6064 & 148.48 \\
Kapal Small 1 & 40.5999 & 1.67 & 36.7885 & 44.8999 & 10.3552 & 162.49 \\
Kapal Small 2 & 44.1801 & 3.73 & 37.6236 & 53.2785 & 7.2599 & 185.71 \\
Kapal X1 & 28.3845 & 3.73 & 20.9295 & 38.9928 & 0.5767 & 172.90 \\
Kapal X2 & 33.7493 & 1.96 & 28.8069 & 37.4109 & 3.9742 & 162.19
\end{tabular}

Gambar 4. Waktu Rata-Rata Keseluruhan Proses Per Tipe Kapal Selama Kapal Berada di Pelabuhan Dari Hasil Simulasi Skenario 1 (Sumber : Hasil Simulasi Data IPT dengan Arena, 2019)

\section{Queue}

Time

\begin{tabular}{lrrrrrr} 
Waiting Time & Average & Half Width & $\begin{array}{r}\text { Minimum } \\
\text { Average }\end{array}$ & $\begin{array}{r}\text { Maximum } \\
\text { Average }\end{array}$ & $\begin{array}{r}\text { Minimum } \\
\text { Value }\end{array}$ & $\begin{array}{r}\text { Maximum } \\
\text { Value }\end{array}$ \\
\hline Anchorage Jetty 1. Queue & 27.2477 & 3.48 & 20.4552 & 38.1855 & 0.02152370 & 132.75 \\
Anchorage Jetty 2. Queue & 31.5824 & 4.27 & 23.4967 & 42.3903 & 0.0981 & 152.08
\end{tabular}

Gambar 5. Waktu Tunggu Kapal untuk Bersandar ke Jetty 1 dan Jetty 2 Dari Hasil Simulasi Skenario 1 (Sumber : Hasil Simulasi Data IPT dengan Arena, 2019) 
INOBIS : Jurnal Inovasi Bisnis dan Manajemen Indonesia

Volume 02, Nomor 04, September 2019

Ibnu Lukman Pratama, Dwi Nurma Heitasari, Ayu Praditha

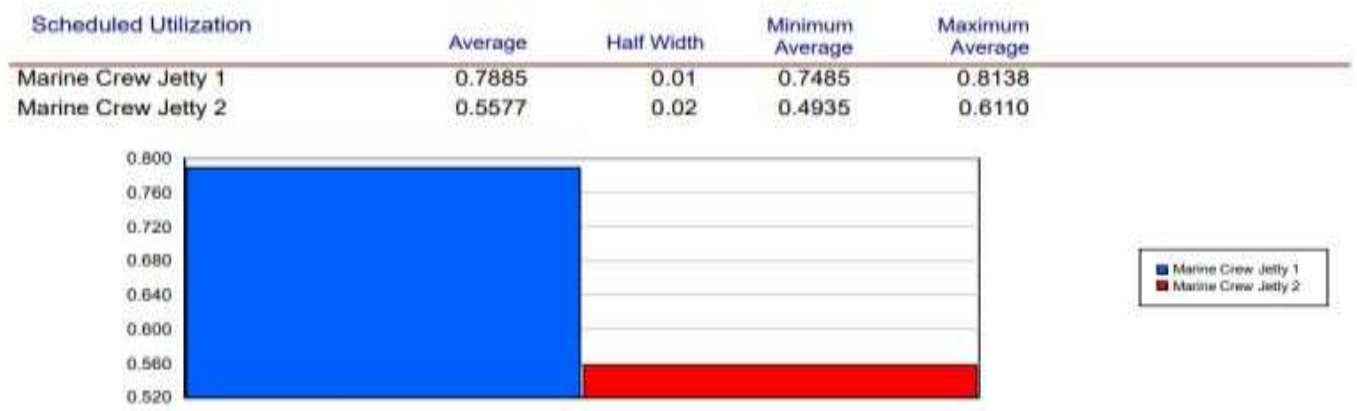

Gambar 6. Utilitas Penggunaan Jetty 1 dan Jetty 2 Dari Hasil Simulasi Skenario 1 (Sumber : Hasil Simulasi Data IPT dengan Arena, 2019)

\section{Skenario 2}

Pada Skenario 2, ditentukan bahwa kapal Small 1 yang semula hanya dapat bersandar di jetty 2 juga dapat melakukan penyandaran di jetty 1, sedangkan Small 2 tetap di jetty 2. Skenario perbaikan ini dapat dilihat pada gambar di bawah ini, garis berwarna putih menunjukkan kondisi eksisting dan garis berwarna menunjukkan skenario perbaikannya

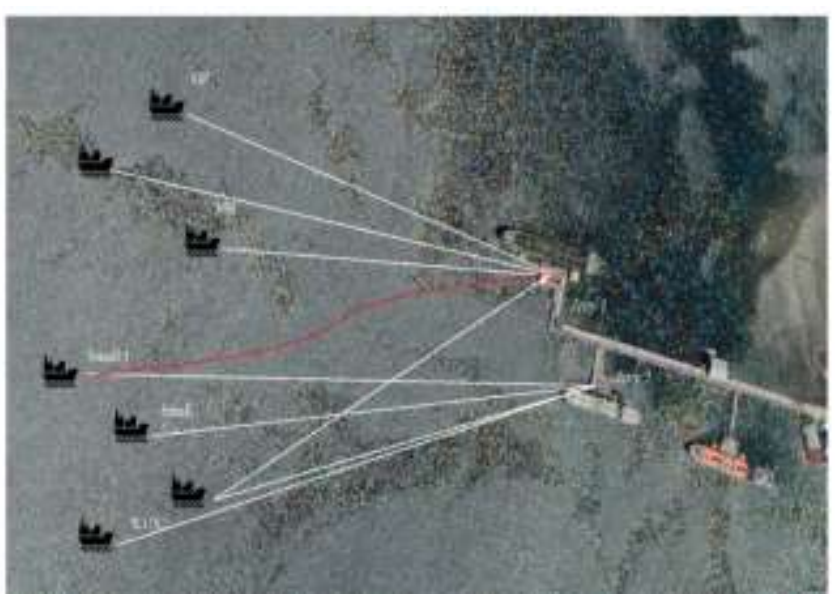

Gambar 7. Skenario 2 Pergerakan Kapal Small 1 Setelah Penambahan Frontal Frame pada Jetty 1 (Sumber : Hasil Olahan, 2019)

Model Simulasi Skenario 2 dapat dilihat pada gambar di bawah ini

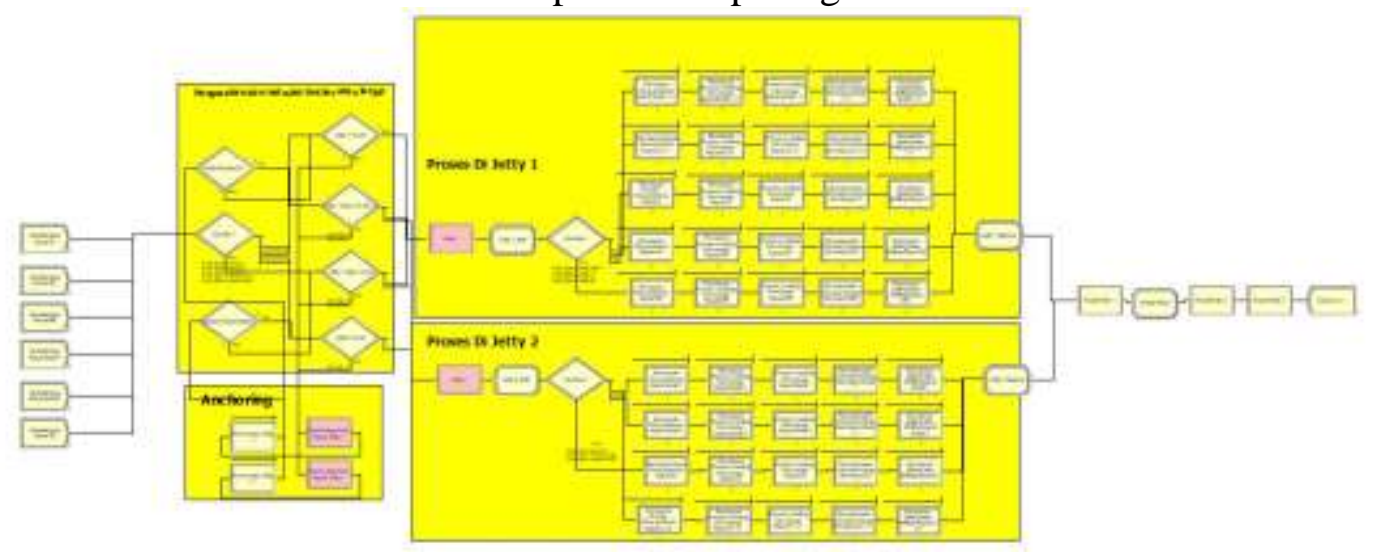

Gambar 8. Model Simulasi Skenario 2 (Sumber : Simulasi Arena Skenario 1, 2019) 
Setelah dilakukan running pada model simulasi skenario 2 didapatkan hasil bahwa waktu rata-rata yang dihabiskan kapal selama berada di pelabuhan mencapai 40,38 jam, waktu tunggu yang dihabiskan kapal untuk masuk ke jetty 1 adalah selama 28,83 jam sedangkan untuk masuk ke jetty 2 adalah selama 29,07 jam dan utilitas jetty 1 adalah sebesar 0,78 sedangkan jetty 2 adalah sebesar 0,78. Adapun kapal yang dilayani adalah sebanyak 492 kapal. Data hasil running pada model simulasi skenario 2 dapat dilihat dibawah ini,

\begin{tabular}{lll}
\hline & \multicolumn{1}{c}{ Values Across All Replications } \\
\hline Unnamed Project & \\
Replications: $10 \quad$ Time Units: Hours
\end{tabular}

\section{Key Performance Indicators}

$\begin{array}{lc}\text { System } & \text { Average } \\ \text { Number Out } & 492\end{array}$

Gambar 9. Jumlah Kapal yang Dilayani Dari Hasil Simulasi Skenario 2 (Sumber : Hasil Simulasi Data IPT dengan Arena, 2019)

\begin{tabular}{lrrrrrr} 
Total Time & Average & Haff Width & $\begin{array}{r}\text { Minimum } \\
\text { Average }\end{array}$ & $\begin{array}{r}\text { Maximum } \\
\text { Average }\end{array}$ & $\begin{array}{r}\text { Minimum } \\
\text { Value }\end{array}$ & $\begin{array}{r}\text { Maximum } \\
\text { Value }\end{array}$ \\
\hline Kapal GP & 51.5536 & 2.77 & 46.5021 & 59.7404 & 13.5471 & 152.52 \\
Kapal MR & 57.0925 & 1.93 & 52.8014 & 61.5192 & 18.9101 & 152.07 \\
Kapal Small1 & 38.5596 & 2.66 & 33.5094 & 45.6737 & 4.9307 & 189.24 \\
Kapal Small 2 & 45.0059 & 2.44 & 39.5210 & 52.6291 & 12.7974 & 162.41 \\
Kapal X1 & 27.2499 & 2.92 & 21.2716 & 34.0012 & 0.8129 & 159.77 \\
Kapal X2 & 31.9536 & 2.42 & 27.5829 & 38.2488 & 3.8116 & 191.77
\end{tabular}

Gambar 10. Waktu Rata-Rata Keseluruhan Proses Per Tipe Kapal Selama Kapal Berada di Pelabuhan Dari Hasil Simulasi Skenario 2 (Sumber : Hasil Simulasi Data IPT dengan Arena, 2019)

\section{Queue}

Time

\begin{tabular}{lrrrrrr} 
Waiting Time & Average & HalfWidth & $\begin{array}{r}\text { Minimum } \\
\text { Average }\end{array}$ & $\begin{array}{r}\text { Maximum } \\
\text { Average }\end{array}$ & $\begin{array}{r}\text { Minimum } \\
\text { Value }\end{array}$ & $\begin{array}{r}\text { Maximum } \\
\text { Value }\end{array}$ \\
\hline Anchorage Jetty 1.Queue & 28.8267 & 2.87 & 22.7119 & 37.6288 & 0.00968382 & 151.74 \\
Anchorage Jetty 2.Queue & 29.0716 & 2.92 & 22.8258 & 36.5340 & 0.01813303 & 153.59
\end{tabular}

Gambar 11. Waktu Tunggu Kapal untuk Bersandar ke Jetty 1 dan Jetty 2 Dari Hasil Simulasi Skenario 2 (Sumber : Hasil Simulasi Data IPT dengan Arena, 2019) 
INOBIS : Jurnal Inovasi Bisnis dan Manajemen Indonesia

Volume 02, Nomor 04, September 2019

Ibnu Lukman Pratama, Dwi Nurma Heitasari, Ayu Praditha

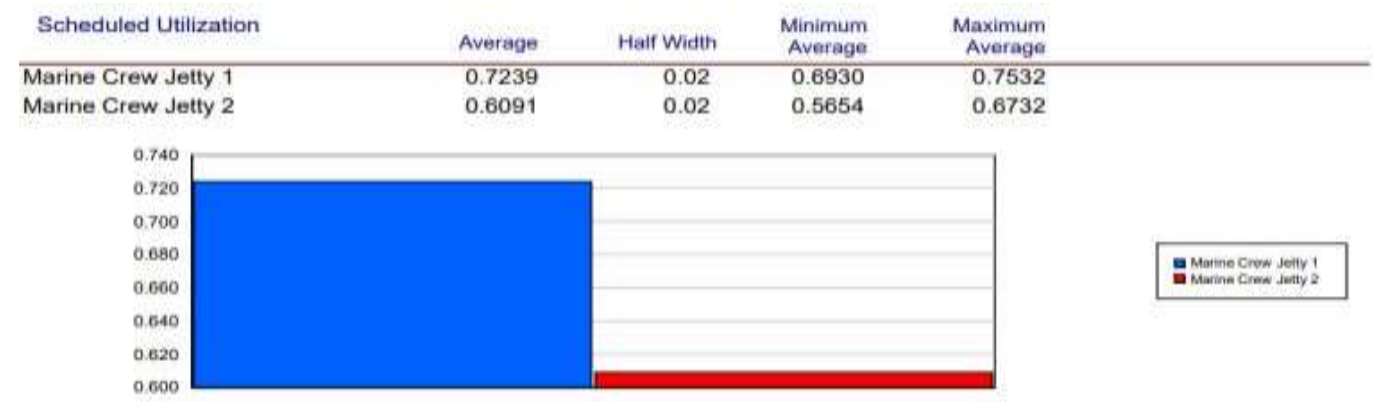

Gambar 12. Utilitas Penggunaan Jetty 1 dan Jetty 2 Dari Hasil Simulasi Skenario 2 (Sumber : Hasil Simulasi Data IPT dengan Arena, 2019)

\section{Skenario 3}

Pada Skenario 3, ditentukan bahwa kapal Small 2 yang semula hanya dapat bersandar di jetty 2 juga dapat melakukan penyandaran di jetty 1, sedangkan Small 1 tetap di jetty 2. Skenario perbaikan ini dapat dilihat pada gambar di bawah ini, garis berwarna putih menunjukkan kondisi eksisting dan garis berwarna menunjukkan skenario perbaikannya.

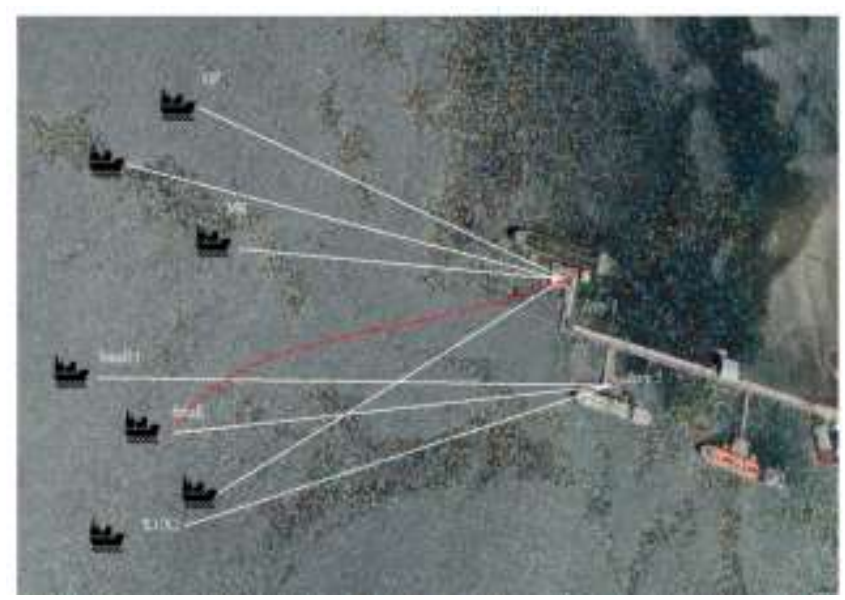

Gambar 13. Skenario 3 Pergerakan Kapal Small 1 dan Small 2 Setelah Penambahan Frontal Frame pada Jetty 1 (Sumber : Hasil Olahan, 2019)

Model Simulasi Skenario 3 dapat dilihat pada gambar di bawah ini

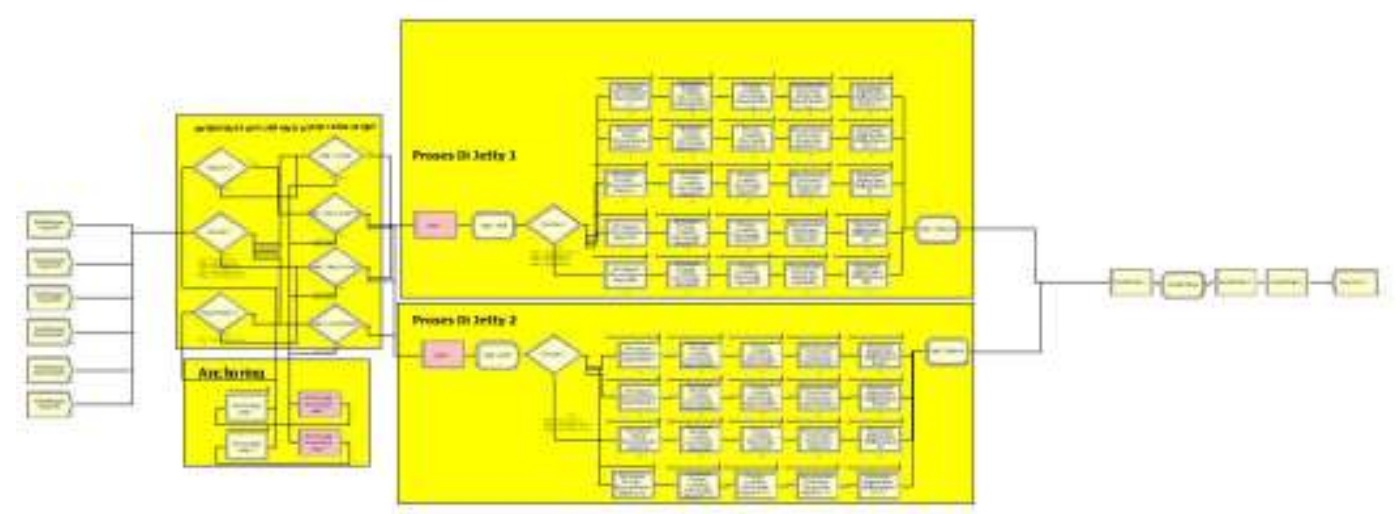

Gambar 14. Model Simulasi Skenario 3 (Sumber : Simulasi Arena Skenario 1, 2019) 
Setelah dilakukan running pada model simulasi skenario 3 didapatkan hasil bahwa waktu rata-rata yang dihabiskan kapal selama berada di pelabuhan mencapai 41,89 jam, waktu tunggu yang dihabiskan kapal untuk masuk ke jetty 1 adalah selama 28,08 jam sedangkan untuk masuk ke jetty 2 adalah selama 32,08 jam dan utilitas jetty 1 adalah sebesar 0,72 sedangkan jetty 2 adalah sebesar 0,62. Adapun kapal yang dilayani adalah sebanyak 494 kapal Data hasil running pada model simulasi skenario 3 dapat dilihat dibawah ini,

\begin{tabular}{ll}
\hline & \multicolumn{1}{c}{ Values Across All Replications } \\
\hline Unnamed Project & \\
\hline Replications: $10 \quad$ Time Units: Hours
\end{tabular}

\section{Key Performance Indicators}

$\begin{array}{lc}\text { System } & \text { Average } \\ \text { Number Out } & 494\end{array}$

Gambar 15. Jumlah Kapal yang Dilayani Dari Hasil Simulasi Skenario 3 (Sumber : Hasil Simulasi Data IPT dengan Arena, 2019)

\begin{tabular}{lrrrrrr} 
Total Time & Average & Half Width & $\begin{array}{r}\text { Minimum } \\
\text { Average }\end{array}$ & $\begin{array}{r}\text { Maximum } \\
\text { Average }\end{array}$ & $\begin{array}{r}\text { Minimum } \\
\text { Value }\end{array}$ & $\begin{array}{r}\text { Maximum } \\
\text { Value }\end{array}$ \\
\hline Kapal GP & 48.9819 & 3.69 & 41.7147 & 56.7819 & 13.4527 & 230.96 \\
Kapal MR & 55.9080 & 4.03 & 46.9789 & 64.1876 & 20.8684 & 236.33 \\
Kapal Small 1 & 44.8219 & 4.25 & 39.3797 & 59.4200 & 11.3298 & 238.52 \\
Kapal Small 2 & 44.8254 & 5.21 & 37.4905 & 63.6404 & 11.5508 & 265.78 \\
Kapal X1 & 27.4965 & 3.06 & 23.5505 & 37.4862 & 1.2807 & 227.32 \\
Kapal X2 & 34.6939 & 5.45 & 26.8670 & 52.1133 & 4.7481 & 254.48
\end{tabular}

Gambar 16. Waktu Rata-Rata Keseluruhan Proses Per Tipe Kapal Selama Kapal Berada di Pelabuhan Dari Hasil Simulasi Skenario 3 (Sumber : Hasil Simulasi Data IPT dengan Arena, 2019)

Queue

Time

\begin{tabular}{lrrrrrr} 
Waiting Time & Average & HalfWidth & $\begin{array}{r}\text { Minimum } \\
\text { Average }\end{array}$ & $\begin{array}{r}\text { Maximum } \\
\text { Average }\end{array}$ & $\begin{array}{r}\text { Minimum } \\
\text { Value }\end{array}$ & $\begin{array}{r}\text { Maximum } \\
\text { Value }\end{array}$ \\
\hline Anchorage Jetty 1.Queue & 28.0774 & 4.48 & 20.2230 & 41.3599 & 0.01244745 & 218.70 \\
Anchorage Jetty 2.Queue & 32.8113 & 6.38 & 24.4924 & 55.9790 & 0.01311006 & 240.28
\end{tabular}

Gambar 17. Waktu Tunggu Kapal untuk Bersandar ke Jetty 1 dan Jetty 2 Dari Hasil Simulasi Skenario 3 (Sumber : Hasil Simulasi Data IPT dengan Arena, 2019) 
INOBIS : Jurnal Inovasi Bisnis dan Manajemen Indonesia

Volume 02, Nomor 04, September 2019

Ibnu Lukman Pratama, Dwi Nurma Heitasari, Ayu Praditha

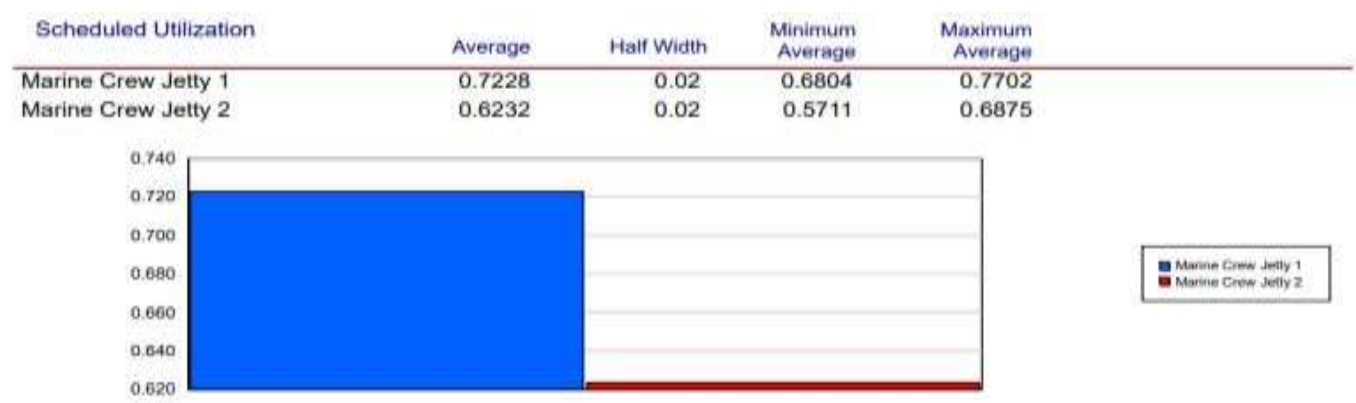

Gambar 18. Utilitas Penggunaan Jetty 1 dan Jetty 2 Dari Hasil Simulasi Skenario 3 (Sumber : Hasil Simulasi Data IPT dengan Arena, 2019)

\section{Perhitungan Biaya Sewa Kapal}

Untuk mengetahui biaya sewa kapal di Integrated Terminal ABC selama tahun 2019 adalah sebagai berikut

Tabel 3. Perhitungan Biaya Sewa Kapal Keseluruhan

\begin{tabular}{|c|c|c|c|}
\hline Jenis Kapal & $\begin{array}{c}\text { Frekwensi } \\
\text { Kedatangan } \\
\text { Kapal Sewa }\end{array}$ & $\begin{array}{c}\text { Charter } \\
\text { Rate } \\
\text { /Kapal/ } \\
\text { Hari (USD) }\end{array}$ & $\begin{array}{c}\text { Charter } \\
\text { Rate/ Kapal/ } \\
\text { Jam (USD) }\end{array}$ \\
\hline GP & 35 & 11.300 & 470,833 \\
\hline MR & 69 & 12.140 & 505,833 \\
\hline Small 1 & 99 & 3.125 & 130,2083 \\
\hline Small 2 & 96 & 5.368 & 223,666 \\
\hline \multicolumn{3}{|c|}{ Rata-Rata Charter Rate/ Jam (USD) } & $85.744,29167$ \\
\hline \multicolumn{3}{|c|}{ Kurs USD ke Rupiah (Rp) } & 14.020 \\
\hline
\end{tabular}

Sumber : Departemen Suplai dan Distribusi MOR I, 2019 (Telah Diolah Kembali)

Sehingga jika dikonversikan ke rupiah maka biaya sewa kapal dapat dilihat pada table dibawah ini,

Tabel 4. Perhitungan Biaya Kapal Eksisting dan Skenario Usulan Per Tahun

Sumber : Hasil Analisis, 2019

\begin{tabular}{|c|c|c|c|}
\hline $\begin{array}{c}\text { Biaya Sewa } \\
\text { Kapal Eksisting/ } \\
\text { Tahun (Rp) }\end{array}$ & $\begin{array}{c}\text { Biaya Sewa } \\
\text { Kapal Skenario } \\
\text { 1/ Tahun (Rp) }\end{array}$ & $\begin{array}{c}\text { Biaya Sewa } \\
\text { Kapal Skenario 2 } \\
\text { / Tahun (Rp) }\end{array}$ & $\begin{array}{c}\text { Biaya Sewa Kapal } \\
\text { Skenario 3 / } \\
\text { Tahun (Rp) }\end{array}$ \\
\hline $\begin{array}{c}85.744,292 \times 52 \times \\
14.020\end{array}$ & $\begin{array}{c}85.744,292 \times 41,5 \\
\text { x 14.020 }\end{array}$ & $\begin{array}{c}85.744,292 \times 40,38 \\
\text { x 14.020 }\end{array}$ & $\begin{array}{c}85.744,292 \times 41,89 \\
\text { x 14.020 }\end{array}$ \\
\hline 62.511 .018 .640 & 49.888 .601 .414 & 48.542 .201 .244 & 50.357 .434 .054 \\
\hline
\end{tabular}

\section{Delta Benefit}

Delta benefit dari penelitian ini didapat dari penghematan waktu sistem kapal (IPT) dan biaya sewa kapal (charter). Penghematan biaya sewa kapal (charter) dihitung dalam setahun untuk perhitungan analisis kelayakan yang didapat dari perkalian rata-rata charter 
rate, waktu sistem kapal (IPT), dan jumlah kapal dalam setahun. Jumlah kapal sewa pada Integrated Terminal ABC adalah sebanyak 476 kapal. Tabel penghematan waktu sistem kapal dan biaya sewa kapal dapat dilihat dari tabel di bawah ini

Tabel 5. Penghematan IPT dari Ketiga Skenario

\begin{tabular}{|c|c|c|}
\hline & IPT & $\begin{array}{c}\text { Penghematan IPT } \\
(\text { Jam })\end{array}$ \\
\hline Eksisting & 52 & - \\
\hline Skenario 1 & 41,5 & $52-41,5=10,5$ \\
\hline Skenario 2 & 40,38 & $52-40,38=11,62$ \\
\hline Skenario 3 & 41,89 & $52-41,89=10,11$ \\
\hline
\end{tabular}

Tabel 6. Penghematan Biaya Sewa Kapal

\begin{tabular}{|c|c|c|}
\hline & $\begin{array}{l}\text { Biaya Sewa } \\
\text { Kapal (Rp) }\end{array}$ & $\begin{array}{c}\text { Penghematan Biaya } \\
\text { Sewa Kapal (Rp) }\end{array}$ \\
\hline Eksisting & 62.511 .018 .640 & - \\
\hline Skenario 1 & 49.888 .601 .414 & $\begin{array}{c}62.511 .018 .640- \\
49.888 .601 .414= \\
12.622 .417 .226\end{array}$ \\
\hline Skenario 2 & 48.542 .201 .244 & $\begin{array}{c}62.511 .018 .640- \\
48.542 .201 .244= \\
13.968 .817 .396\end{array}$ \\
\hline Skenario 3 & 50.357 .434 .054 & $\begin{array}{c}62.511 .018 .640- \\
50.357 .434 .054= \\
12.153 .584 .586\end{array}$ \\
\hline
\end{tabular}

Sumber : Hasil Analisis, 2019

Tabel 7. Penghematan Waktu IPT

\begin{tabular}{|c|c|c|c|}
\hline Parameter & $\begin{array}{c}\text { Skenario 1 (Small 1 } \\
\text { \& 2 dapat } \\
\text { bersandar ke Jetty } \\
\text { 1) }\end{array}$ & $\begin{array}{c}\text { Skenario 2 } \\
\text { (Hanya Small 1 } \\
\text { yang dapat } \\
\text { bersandar ke Jetty } \\
\text { 1, Small 2 tetap di } \\
\text { Jetty 2) }\end{array}$ & $\begin{array}{c}\text { Skenario 3 (Hanya } \\
\text { Small 2 yang } \\
\text { dapat bersandar } \\
\text { ke Jetty 1, Small 1 } \\
\text { tetap di Jetty 2) }\end{array}$ \\
\hline $\begin{array}{c}\text { Penghematan } \\
\text { IPT (Jam) }\end{array}$ & 10,5 & 11,62 & 10,11 \\
\hline
\end{tabular}

Sumber : Hasil Analisis, 2019 
Tabel 8. Penghematan Biaya Sewa Kapal

\begin{tabular}{|c|c|c|c|}
\hline Parameter & $\begin{array}{c}\text { Skenario 1 (Small 1 } \\
\text { \& 2 dapat } \\
\text { bersandar ke Jetty } \\
\text { 1) }\end{array}$ & $\begin{array}{c}\text { Skenario 2 } \\
\text { (Hanya Small 1 } \\
\text { yang dapat } \\
\text { bersandar ke Jetty } \\
\text { 1, Small 2 tetap di } \\
\text { Jetty 2) }\end{array}$ & $\begin{array}{c}\text { Skenario 3 (Hanya } \\
\text { Small 2 yang } \\
\text { dapat bersandar } \\
\text { ke Jetty 1, Small 1 } \\
\text { tetap di Jetty 2) }\end{array}$ \\
\hline $\begin{array}{c}\text { Penghematan } \\
\text { Biaya Sewa } \\
\text { Kapal (Rp) }\end{array}$ & 12.622 .417 .226 & 13.968 .817 .396 & 12.153 .584 .586 \\
\hline
\end{tabular}

\section{Kesimpulan}

Skenario penambahan frontal frame pada jetty 1 untuk menurunkan Integrated Port Time (IPT) pelabuhan di Integrated Terminal ABC pada penelitian ini menggunakan 3 skenario. Skenario simulasi proses aktivitas kapal di pelabuhan yang paling efektif untuk menurunkan Integrated Port Time (IPT) di Integrated Terminal ABC adalah Skenario 2. Dari Aspek Teknis dan Finansial, skenario 2 paling banyak memberikan penghematan baik itu penghematan IPT ataupun biaya sewa kapal. Adapun penghematan IPT yang dapat dilakukan pada skenario 2 adalah sebesar 11,62 jam sehingga nilai IPT yang semula 52 jam menurun menjadi 40,38 jam. Sedangkan penghematan biaya sewa kapal yang dapat dilakukan pada skenario 2 adalah sebesar Rp 13.968.817.396, dan utilitasnya yang semula masing-masing jetty adalah sebesar 0,53 dan 0,81 , dengan skenario 2 utilitasnya menjadi lebih baik yaitu 0,72 dan 0,61 hal ini menandakan bahwa kedua jetty telah digunakan dengan baik dalam artian tidak terlalu banyak menganggur dan tidak terlalu sibuk.

\section{Daftar Pustaka}

2010. Pedoman Integrated Port Time (IPT) No. A-009/F20000/2010-S0 Revisi $K e-0$. Jakarta : PT Pertamina Shipping.

Bridgestone Corporation. 2011. Marine Fender Catalogue. Tokyo-Japan.

Dewan Energi Nasional. 2019. Outlook Energi Indonesia (EOI). Jakarta : Sekretariat Jendral Dewan Energi Nasional.

Kelton, W. D., Sadowski R. P., and Sturrock, D. T. 2007. Simulation with Arena. Keempat Penyunt. New York : McGraw Hill.

Saputra, Bobby Chandra. 2015. Studi Simulasi Proses Pemuatan dan Penimbangan Kontainer Ekspor dengan Tujuan Meminimalkan Stapel (Studi Kasus : PT WINA Gresik). Jurnal Matrix, 16 (1), 9-18. doi : 10.3587/matrix.vI6i.xxx..

Triadmojo, Bambang. 2009. Perencanaan Pelabuhan. Teknik Sipil Universitas Gadjah Mada. Yogyakarta : Beta Offset.

Wahid, Ririan Safiadi. 2011. Evaluasi Kondisi Lingkungan dan Olah Gerak Kapal Terhadap Kerusakan Fender pada Pelabuhan Merak. Tugas Akhir. Fakultas Teknik Program Studi Teknik Sipil. Universitas Indonesia. 